disorientated running is succeeded by a clonic phase or by clonic-tonic convulsions, terminating either in a spastic state, catalepsy or exhaustion.

Our studies on a strain of epileptic Peromyscus (maniculatus-artemesisice, received from Dr. L. R. Dice, Ann Arbor, Michigan) have revealed a new component of the behaviour in the post-convulsive phase. While convulsing two litter-mate animals together in the same enclosure, the animal which recovered first from the fit made a savage attack on the other, biting and holding it with the fore-paws.

Typically we have observed 'bouncing' convulsions lead to a prostrate clonic phase during and after which the jaws of the mouse are con stantly in motion, and it may sometimes bite its own feet. The animal recovers while still undergoing clonic movements, and then runs and hops round the cage with retroverted head. In this phase it will follow and attack other mice or attack models and occasionally attempts to bite the floor. Sometimes the attacks are interrupted by clonic movements which loosen its hold on the attacked object. Otherwise it may erawl over the model, attacking it in many places, or make repeated sallies at the same model. Finally, it halts, shaking with ears extended, hairs on the back erect and with its head and tail raised.

Referring to the latter part of the 'bouncing' fits, Watson ${ }^{5}$ says, "After 5 to 20 seconds of clonic convulsions most of the mice in this condition will take hold of the cotton which surrounds the tin enclosure in which they are tested; they hang along the cotton with their feet or teeth for several minutes until they are able to walk away". This attitude, we suggest, is really an attack. Hamilton ${ }^{2}$, describing the postconvulsive symptoms of his rats, mentions that "After the convulsive attack the animal relapses into a 'coma' which may last from a few seconds to as long as thirty minutes. If it is of short duration the animal usually is subsequently hypersensitive, squealing, jumping and biting violently when touched," and "During the later stages of the coma the animal may make aimless head movements from side to side or chew on objects that reach his mouth, such as sawdust, other rats, his own paws and frequently his tail, which because of a characteristic sitting position is readily accessible".

This behaviour is in many respects the same as that discovered by us, except that the 'coma' prevents the animal from making an assault. Apparently, observers working with Peromyscus have missed this component of the fits because they have only reported observations on solitary animals. Later work on a number of animals of both sexes has confirmed our original observation, the aggression occurring towards the end of a 'bouncing' clonic convulsion with marked regularity in young animals. Not only do they make attacks on cage mates which are not attacked between fits, but they chase and attack other mice. The attacks are also made on models and in the presence of a number of different models, such as a stuffed Peromyscus pelt, a cotton-wool roll and a 'Plasticine' model; the wool- and fur-covered models are attacked preferentially. The aggression is, therefore, part of a co-ordinated phase of behaviour and is thus an automatism. This suggests that the hopping and running of the mice in this phase are also automatic phenomena, due to a "return of activity to the lower centres" before the derangement of the neural mechanism has been restored to normal ${ }^{6}$.

In view of the close similarity of audiogenic convulsions in Peromyscus and rats, it would be interest- ing to know if post-convulsive aggression occurs in any of the different strains of rats subject to this type of abnormal behaviour.

As aggression is a component of post-ictal automatisms in $\operatorname{man}^{6}$, the discovery of an aggression in the behaviour of Peromyscus following audiogenic seizures adds a further point to the evidence suggesting a close similarity between this type of abnormal behaviour in rodents and epilepsy in man.

$$
\begin{gathered}
\text { Pharmacology Department, } \\
\text { Medical School, } \\
\text { University of Birmingham. } \\
\text { Sept. 26. }
\end{gathered}
$$

M. R. A. Chance

${ }^{1}$ Maier, N. R. F., "Studies of Abnormal Behaviour in the Rat" (Harper Bros., 1939).

${ }^{2}$ Hamilton, J. R., J. Comp. Psychol., 33297 (1942).

${ }^{3}$ Hall, C. S., and Martin, R. F., J. Psychol., 10, 207 (1940).

' Griffiths, W. J., jun., J. Comp. Psychol. Monographs, 17, No. 8, SN92 (1942).

${ }^{5}$ Watson, M. L., Contributions from the Laboratory of Vertebrate Genetics, No. 11 (July 1939). 'Penfleld, W., and Erickson, T. C., "Epilepsy and Cerebral Localisa-
tion" (1941).

\section{Absorption of Protein and Bacteria from Normal and Infected Joints}

KNEE joints of rabbits were infected by intraarticular injection of staphylococci. In some cases a diluted solution of a standardized staphylococcus filtrate was used instead. The absorption of protein from the joint cavity was tested by means of $\mathbf{5 . 5} \mathrm{gm}$. per cent solution of human hæmoglobin in isotonic saline containing $10 \mathrm{mgm}$. per cent of calcium. Living radioactive bacteria used in absorption tests were prepared by growing Mycobacterium phlei on a Sauton substrate containing radiophosphorus.

The following observations were made. During the first hour of infection, the absorption of hæmoglobin is increased above normal. Two to three hours after infection, the rate of absorption of hæmoglobin is temporarily decreased below normal. The decrease lasts only a few hours. Heparinization of the animals prevents this decrease of absorption; instead, an increased absorption of hæmoglobin, as great as during the first hour after infection, prevails for several hours. The absorption of radioactive bacteria injected one hour after the infection is greatly reduced whether heparin is given or not. In joints inflamed by means of a diluted culture filtrate, the absorption of hæmoglobin is increased far above normal. This increase is partly prevented by large doses of desoxycorticosteroneacetate. Desoxycorticosteroneacetate, however, has no effect on the absorption of hæmoglobin from normal joint cavities.

The results confirm previous statements by Men$\mathrm{kin}^{1}$ that in staphylococcus inflammation the absorption of colloids is partly blocked by fibrin clots. The formation of these clots is prevented by heparin. The fact that the absorption of radioactive bacteria is blocked in spite of heparin shows that this block has a different origin. Control experiments on benzene-poisoned animals are in progress in order to investigate if the partly blocked absorption of bacteria depends on leucocytic action.

\section{Institute of Physiology,}

TORBJÖRN EDLUND

University of Uppsala.

Sept. 27.

${ }^{1}$ Menkin, V., J. Exp. Med., 58, 171 (1931). 